\title{
Correction to: Rapid molecular detection of pathogenic microorganisms and antimicrobial resistance markers in blood cultures: evaluation and utility of the next-generation FilmArray Blood Culture Identification 2 panel
}

Tanja Holma ${ }^{1}$ Jukka Torvikoski ${ }^{1}$. Nathalie Friberg ${ }^{1} \cdot$ Annika Nevalainen $^{1} \cdot$ Eveliina Tarkka ${ }^{1}$ Jenni Antikainen ${ }^{1}$. Jari J. Martelin ${ }^{1}$

Published online: 8 February 2022

(c) Springer-Verlag GmbH Germany, part of Springer Nature 2022

Correction to: European Journal of Clinical Microbiology \& Infectious Diseases

https://doi.org/10.1007/s10096-021-04314-2

The originally published article was published with errors and missing information due to lapses during submission process. The errors are listed below:

1) The section "Clinical samples" has errors and missing sentences.

2) The fifth paragraph of Discussion section is missing.

3) There are missing sentences in the last paragraph of the Discussion section.

The original article has been corrected.

Publisher's note Springer Nature remains neutral with regard to jurisdictional claims in published maps and institutional affiliations.

The original article can be found online at https://doi.org/10.1007/ s10096-021-04314-2

Tanja Holma

tanja.holma@hus.fi

HUS Diagnostic Center, HUSLAB, Department of Clinical

Microbiology, University of Helsinki and Helsinki

University Hospital, Helsinki, Finland 